\title{
A Educação na mídia: o espaço da polêmica e da verdade
}

Carlos Alberto BAPTISTA

O poder nunca depende de um único indivíduo, mas da instância na qual se encontra o indivíduo e de onde ele tira sua força (Patrick Charaudeau).

\section{Considerações iniciais}

A Educação é um tema tratado frequentemente na esfera midiática. Artigos, reportagens, documentários abordam, sob diferentes perspectivas, a situação da Educação no país e a dos profissionais que nela atuam. Um dos motivos desse interesse midiático 
pelo tema pode ser explicado pelo fato de, ao interessar-se pela Educação, o veículo midiático valoriza sua imagem como preocupado com o plano social. Isso faz com que a Educação seja um tema legitimador para a instituição jornalística.

Para tratar da Educação, a imprensa dá voz a enunciadores, não somente internos, mas também externos a ela, ou seja, àqueles que não fazem parte do corpo editorial da revista. A instância midiática, na medida em que disponibiliza espaço e voz a esses enunciadores, legitima-os como autoridade competente capaz de dizer sobre a problemática educacional. No entanto, é preciso interrogar quais os lugares de fala dos sujeitos que enunciam acerca da Educação. Em outras palavras, é preciso pensar em termos de campos e posicionamentos discursivos de sujeitos que ocupam posições legitimadoras do dizer sobre o campo da educação, logo, considerar posicionamentos em ampla concorrência. Tendo isso em vista, temos como objetivo analisar como se constituem os posicionamentos sobre a Educação veiculados em discursos da revista Veja e, em particular, identificar o funcionamento enunciativo do posicionamento econômico-educacional.

Foi essa inquietação que nos levou, em Baptista (2015), a buscar compreender o que faz com que um economista tenha autoridade para enunciar sobre a Educação e receber a legitimidade nesse campo discursivo. Naquela ocasião, analisamos os discursos de Claudio de Moura Castro publicados na revista Veja. O presente artigo emerge, assim, ao amadurecemos a ideia de que há um discurso sobre a educação na mídia do Brasil e de que esse discurso funciona por lugares de fala constituídos historicamente.

No entanto, naquela pesquisa surgiram problemáticas que buscamos contornar e adequar os dispositivos analíticos. O primeiro ponto é o de pensar a Educação como campo discursivo. E consequentemente as características particulares desse campo que, por 
sua vez, permite um tipo de enunciação próprio com determinados entrecruzamentos de outros discursos e de formas de organização, domínio e poder.

Outro ponto que apareceu como necessidade a esta pesquisa é a adequação de dispositivos para o exame das relações interdiscursivas e de poder que atravessam este discurso. Nesse sentido, parece-nos que a noção de interincompreensão e principalmente a de simulacro, desenvolvidas por Maingueneau (2008a) dão conta de aspectos já identificados anteriormente, mas pouco explorados.

Tendo isso em vista, examinamos em recortes do artigo "O que pensam os professores brasileiros”, publicado na Veja.com, como o enunciador articula interdiscursivamente seu enunciado por meio de semas do posicionamento ao qual adere - econômico-educacional - e em oposição aos semas do posicionamento antagônico ao seu - pedagógico-educacional -, marcando, dessa forma, seu lugar de fala. Ressaltamos a originalidade deste estudo acerca do discurso educacional, tendo em vista que, embora seja um discurso tópico nas práticas sociais, é pouco explorado pelos analistas do discurso.

Organizamos o capítulo em três etapas: em primeiro lugar, desenvolvemos a fundamentação teórica em torno dos conceitos de interdiscurso, interincompreensão e simulacro, conforme propõe Maingueneau (2008a); depois, discorremos sobre o discurso educacional como campo discursivo e apontamos os posicionamentos que atuam no espaço discursivo dos discursos sobre a Educação, no corpus selecionado; por fim, analisamos o processo pelo qual os posicionamentos interagem no campo educacional. 


\section{O primado do interdiscurso e a polêmica discur- siva}

A relação com o Outro como fundamento da discursividade tornou-se um fenômeno aceitável em todas as vertentes e disciplinas do discurso. Desse modo, o conceito de interdiscurso ganhou cada vez mais espaço e relevância nos estudos discursivos, o que levou Maingueneau (2008a) a elevá-lo à categoria primordial.

Desse modo, nos estudos atuais da Análise do Discurso, Maingueneau (2008a), propõe o primado do interdiscurso sobre o discurso como um dos princípios basilares, o que quer dizer que o discurso só adquire sentido na relação que estabelece com outros, pois é nessa relação que se funda sua identidade. Por essa perspectiva, os discursos não nascem de modo independente e depois interagem. Na verdade, sua gênese se constitui no bojo do interdiscurso. Partindo-se dessa hipótese, a unidade de análise passa a ser o interdiscurso e não o discurso. Além disso, o acréscimo, que Maingueneau nos fornece, deve-se em especial ao fato de dar maior operacionalidade à noção de interdiscursividade.

Para isso, o que Maingueneau propõe é especificar o interdiscurso em uma tríade: o universo discursivo, o campo discursivo e o espaço discursivo. Nessa tríade é possível refletir sobre o funcionamento discursivo, concebendo-o, na sua gênese, como um espaço de interação que precisa ser identificado e delimitado pelo pesquisador.

Como universo discursivo, Maingueneau (2008a) define um conjunto de posicionamentos de diferentes ordens que interagem em uma conjuntura. Se considerarmos o discurso educacional por exemplo, poderíamos identificar interações como aquelas imanentes dos posicionamentos do campo da Política, da Economia, da 
Filosofia, da Psicologia, da Sociologia, da Religião, dentre outros. Contudo, delinear o extenso processo discursivo não seria muito produtivo. Por isso, Maingueneau (2008a, p. 35) considera que o universo discursivo é de "pouca utilidade para o analista", mas é a partir do universo discursivo que podemos nos defrontar com "domínios susceptíveis de análise", quais sejam: os campos discursivos.

O campo discursivo, na verdade, é uma região do universo discursivo em que um conjunto de posicionamentos encontra-se em concorrência. São discursos que possuem a mesma função social e divergem sobre o modo pela qual ela deve ser preenchida. $\mathrm{O}$ campo é perpassado por diversos posicionamentos, que disputam e definem em conjunto o funcionamento do campo. Esse é um lugar aberto de tensões e de embates, pois, correntes, pensamentos, doutrinas, partidos encontram-se em conflito e em aliança.

A noção de posicionamento empregada neste capítulo assume os sentidos de instauração e conservação de uma identidade enunciativa, conforme Charaudeau \& Maingueneau (2008). O posicionamento implica, ainda, conforme Maingueneau (2008b) uma tomada de posição em determinado campo discursivo, o que resulta numa definição identitária do sujeito em relação aos outros que compõem o campo. Trata-se da disputa em "território simbólico" contra posicionamentos antagônicos.

Com efeito, é no interior do campo discursivo que um discurso é constituído. Essa constituição ocorre, como supõe Maingueneau (2008a, p. 36) de acordo com operações regulares no âmago de posicionamentos já existentes. A hipótese é de que se busque identificar essas operações, porém, o campo discursivo é uma região muito vasta e inconstante, por isso, o analista deve isolar, no campo, os posicionamentos que ele julga relevantes. Trata-se do espaço discursivo, recorte hipotético feito pelo analista. Essa hi- 
pótese deve ser fundamentada sobre um conhecimento histórico e discursivo construído pelo estudo das condições sócio-históricas de produção do discurso.

No espaço discursivo, é possível identificar como posicionamentos específicos interagem, ou seja, o modo como um discurso retoma o Outro, fundando-se na heterogeneidade. Contudo, o processo interativo não acontece de forma aleatória, pois ele respeita as regularidades específicas de cada posicionamento discursivo. As regularidades são definidas como restrições semânticas que marcam a identidade de cada posicionamento. Quando se analisa o espaço discursivo e o processo interdiscursivo, o que se nota é que os posicionamentos em interação no espaço se relacionam por um processo regrado de interincompreensão. Isto é, um posicionamento retoma o discurso do Outro no seu interior, de acordo com as suas próprias regras semânticas. Assim, cria-se um processo de tradução em que o discurso do Outro é transposto de acordo com as regras do posicionamento agente.

De fato, há uma interincompreensão regrada, o que quer dizer que enunciar a partir de um discurso, é enunciar em conformidade com as regras de um posicionamento e, ao mesmo tempo, em contraste às regras de seu Outro. Há, portanto, sempre um discurso agente, que se encontra em posição de tradutor, e um discurso-paciente, aquele que é traduzido. E é sempre em benefício do discurso agente que a tradução ocorre, ou seja, os "semas positivos" do Outro, seus pontos de vista e modo de conceber o mundo, são traduzidos em "semas negativos: modos de depreciação e de desvalorização. Os traços negativos não são e não existem no Outro, mas o modo que são traduzidos pelo discurso agente em forma de simulacros. 


\section{O campo da Educação}

Pensar a Educação como um campo, ou ainda, pensar no campo discursivo educacional, requer certos cuidados, pois a noção de Educação engloba instâncias muito diversas: as instituições físicas (os prédios, as escolas e as universidades), seus agentes (professores, gestores, orientadores, ministros), o domínio político-educacional (legislações, estatutos) e a ciência da educação, ou discurso pedagógico (teorias e estudos sobre aspectos cognitivos, didáticos etc.). Todas essas instâncias atuam de algum modo para a constituição de um campo discursivo educacional, que reúne, assim, discursos que emergem de lugares diversos da sociedade: está na fala do professor, do ministro da educação e do especialista que toma a Educação como seu objeto de estudo.

Esses agentes e as instituições de onde emanam seus discursos são marcados pelas especificidades dos campos de onde falam, como o campo científico na fala do especialista e do campo político na fala do ministro, por exemplo. Por isso, não é possível pensar no campo da Educação como um lugar homogêneo, pois é atravessado por uma rede interdiscursiva que marca sua identidade. Uma das características que podemos notar, portanto, acerca do campo discursivo educacional, é a heterogeneidade que o constitui, caracterizando-o como um campo híbrido, delimitado e definido por posicionamentos advindos também de outros campos sociais.

Além disso, ao se pensar a Educação como um campo discursivo, é necessário identificar que esse campo é formado por posicionamentos em concorrência que buscam definir o sentido da Educação. Os posicionamentos podem ser pensados em dominantes e dominados, visto que há aqueles com maior legitimidade em determinadas condições sócio-históricas.

Destarte, em cada conjuntura sócio-histórica, as forças he- 
gemônicas no campo do poder, isto é, os posicionamentos com maior legitimidade estruturam o discurso educacional. É nesse sentido que o discurso religioso, o discurso político-patriótico e o discurso político-econômico assumiram, em momentos diferentes, um lugar de maior domínio sobre o discurso educacional.

$\mathrm{Na}$ atual conjuntura, conforme acentuamos em Baptista (2015, p. 8), os posicionamentos do discurso econômico, infiltrados na instância política, tornam-se decisivos para nortear o campo educacional.

Embora a economia e a educação sejam campos discursivos distintos, em uma sociedade de organização econômica capitalista, em que a qualidade de vida passa a depender, cada vez mais, do sistema econômico, o campo da economia assume um lugar privilegiado, que legitima também seus representantes.

Separamos, assim, no espaço interdiscursivo do campo educacional, dois posicionamentos em conflito: o do discurso econômico-educacional e o do discurso pedagógico educacional.

O posicionamento econômico-educacional, dominado pelo posicionamento neoliberalista advindo da economia, com base nos estudos teóricos da Economia da Educação, coloca o sistema educacional no mesmo plano de outras atividades econômicas, visto que ele consome uma proporção dos recursos escassos da sociedade. Ao considerar isso, aplica o raciocínio de mercado ao sistema educacional, isto é, analisa a relação custo-benefício, para se mensurar até que ponto é vantajoso investir em Educação. Surge, então, desse posicionamento, a noção de capital humano, cujo 
sentido tem como base a ideia de que a Educação tem o objetivo de desenvolver economicamente um país.

Em contraste a esse posicionamento, o discurso pedagógico-educacional, com base em pensadores das Ciências Humanas, defende a educação como forma de desenvolvimento do indivíduo crítico e autônomo. Critica, portanto, a influência político-econômica na Educação e aponta os limites da teoria do capital humano. Denuncia o reducionismo econômico, por trazer consequências desastrosas à sociedade, como a precariedade do sistema público de ensino, as péssimas condições de trabalho dos agentes da Educação e, consequentemente, a desigualdade na distribuição de renda entre as classes sociais.

Para nossa análise, selecionamos o artigo "O que pensam os professores brasileiros" publicado na Veja.com, em 2012, de autoria de Gustavo Ioschpe, colaborador da revista desde 2006. No artigo, o autor traz dados de pesquisas feitas com professores brasileiros, visando, assim, a desconstruir a imagem da doxa de professor em contraste com aquela apontada nas pesquisas.

No corpus analisado, a propósito de identificar o funcionamento enunciativo do posicionamento econômico-educacional, buscamos evidenciar o embate entre os dois posicionamentos de modo separado: o modo pelo qual o discurso verificado retoma o Outro não do modo como ele é em sua identidade, mas de acordo com o lugar de fala do enunciador. $\mathrm{Na}$ análise, portanto, o posicionamento econômico-educacional é tomado como o lugar de fala do enunciador. O discurso do Outro, neste caso, é o dos professores, cujo lugar de enunciação é o posicionamento pedagógico-educacional. 


\section{A produção enunciativo-interdiscursiva do posi- cionamento econômico-educacional}

No recorte 1 o enunciador recorre a dados numéricos para embasar seu ponto de vista. Esse aspecto está presente em todo seu discurso e atua para a construção de um lugar de fala legítimo.

\section{Recorte 1}

As pessoas que optam pela carreira de professor não são derrotadas. Pelo contrário, são profundamente idealistas. Querem mudar o mundo, mudando a vida de seus alunos. Quase três quartos dos professores (72\%) acham que uma das finalidades mais importantes da educação é "formar cidadãos conscientes". Nove entre dez professores concordam que "o professor deve desenvolver a consciência social e política das novas gerações". Apenas $45 \%$ acreditam que "o professor deve evitar toda forma de militância e compromisso ideológico em sala de aula".

O enunciador marca, pelo recurso no campo da estatística, seu lugar de fala: dos das informações porcentuais e da cientificidade garantida pela pesquisa quantitativa. Os dados atribuem legitimidade ao seu dizer. Essa recorrência, presente em todo o discurso analisado, inscreve seu posicionamento no campo da Economia, que, para fortalecer sua cientificidade, recorre à Matemática e à Estatística.

Sutter (2007), em pesquisa realizada, aponta que em dez dos mais conceituados jornais econômicos, somente 5,8\% dos artigos 
publicados entre 2003 e 2004 não usavam a análise estatística de dados e expressões matemáticas. A interdiscursividade entre Economia, Matemática e Estatística faz com que a Economia pleiteie um lugar entre as ciências exatas ou, pelo menos, esteja na fronteira entre elas e as Ciências Sociais. Não obstante, por estar determinada pelas ações humanas, a Economia não deixa de ser, a priori, uma ciência social.

E há, aliás, quem condene o uso abusivo da Matemática pela Economia, conforme atesta Emerick (2013, p. 52), ao dizer que os economistas usam a Matemática como forma de intimidação retórica e "uma arma para autolegitimização de um discurso pseudocientífico", já que os números apresentam-se como verdades absolutas e indiscutíveis. Coaduna com essa opinião a visão de Bresser-Pereira (2009), para quem, há vinte anos, a Economia desastrosamente vem abusando da Matemática, por acreditar que só assim seja possível de se fazer ciência. Para este pesquisador, é necessário observar as tendências históricas e não simplesmente aplicar métodos.

O posicionamento assumido pelo enunciador, embora atue enunciativamente como representante do campo educacional, não deixa de ser marcado pelo campo legitimador da Economia. Por isso, é influenciado, mesmo que não perceba, pelo modo de enunciar no campo econômico, o que justifica a recorrência a tais dados numéricos. No campo econômico ou no campo educacional, indiferentemente, para o enunciador somente há verdade nos dados quantitativos. Esses dados garantem a cientificidade de sua enunciação e, consequentemente, sua legitimidade.

Ainda nesse recorte, notamos como o enunciado dos professores (discurso paciente) é introduzido no discurso do enunciador (discurso agente): "formar cidadãos críticos". O enunciador enfatiza que esse posicionamento é da maioria dos professores com 
o uso da expressão "quase três quartos" seguido do porcentual (72\%). O item lexical "quase" fortalece a ideia de que a maioria dos professores compactua com essa opinião.

Em seguida, complementando o enunciado anterior, o enunciador mobiliza novamente o discurso paciente, "nove entre dez professores concordam que 'o professor deve desenvolver a consciência social e política das novas gerações"'. O enunciador ressalta novamente, com a expressão numérica, a ideia de que os professores acreditam que um de seus papéis é a formação de opinião dos alunos. Notemos que no enunciado "formar cidadãos conscientes", não é especificado o sentido de "cidadãos conscientes", mas no enunciado seguinte esse sentido é evidenciado como "desenvolver consciência social e política”.

Somente no último enunciado, o enunciador traz o posicionamento antagônico ao primeiro: o dos professores que discordam de que devem ser formadores de opinião e apresentar posicionamentos políticos. Notemos que, embora seja quase a metade (45\%), o enunciador qualifica como "apenas", destacando a ideia de minoria. Assim, mesmo o enunciador não evidenciando de modo explicito seu posicionamento, pelo modo como enuncia as informações no discurso, transparece que ele orienta o co-enunciador a aderir à ideia de que a maioria dos professores acredita que deve influenciar "ideologicamente" seus alunos.

Deve-se levar em conta que o lugar de fala que o enunciador atribui aos professores é constituído pelo próprio lugar de onde ele enuncia. Assim, seu posicionamento lê o Outro apenas pelo filtro de seu próprio lugar. Há, nesse processo, o enquadramento do lugar do Outro: o enunciador atua para fazer com que os coenunciadores de seu discurso adiram à ideia de que os professores enunciam de um lugar de fala específico no interdiscurso: o posicionamento de um grupo idealista que atribui um papel específico 
à educação, isto é, o objetivo que os professores veem na educação é de desenvolver a consciência política e influenciar ideologicamente seus alunos.

O enunciador, portanto, em primeiro lugar, enquadra os professores no posicionamento pedagógico-educacional, como idealistas. Sequencialmente, desqualifica o enunciado que atribui ao posicionamento pedagógico-educacional "formação crítica", traduzindo-o como "militância e compromisso ideológico em sala de aula”. As noções de militância e compromisso ideológico atuam neste discurso como o simulacro que o discurso agente produz do discurso paciente. Traduzir "formação crítica" por militância ideológica é desqualificar o Outro, fazer com que o lugar do outro seja depreciado.

Contudo, a desvalorização do posicionamento antagônico (discurso paciente) somente ocorre em referência ao próprio posicionamento agente. Assim, é o posicionamento econômico-educacional que atua como filtro. Isto é, quem enuncia do posicionamento econômico-educacional adere à ideia de que a Educação tem o "objetivo de transmissão de conteúdo conceitual e técnico". Logo, o que é posto por outro discurso, que destoe desse ponto de vista, é desqualificado por esse posicionamento. Assumir um posicionamento é, deste modo, assumir pontos de vista legítimos e identificar os do Outro como falsos. 


\section{Recorte 2}

Os professores estão falhando na sua tarefa mais simples, que é transmitir conhecimentos e desenvolver as capacidades cognitivas de seus alunos (...). Só 32\% deles concordariam em dizer "meus alunos aprendem de fato". Dois terços dos professores admitem que só conseguem desenvolver entre $40 \%$ e $80 \%$ do conteúdo previsto no ano. Só um terço coloca esse patamar acima de $80 \%$.

De acordo com o posicionamento econômico-educacional, o que é valorizado nesse discurso é a educação enquanto transmissão de conteúdo e desenvolvimento de capacidades cognitivas. $\mathrm{O}$ tema "finalidade da educação e papel dos professores" é assim definido pelo enunciador. Portanto, o enunciador opõe-se à Educação que valoriza o desenvolvimento do senso crítico, conforme subentendido no recorte 1 , por considerar esse ponto de vista sobre o tema como ilegítimo.

O enunciado do recorte 2 esclarece a orientação que o enunciador dá ao enunciado apresentado no recorte 1 . Ao enfatizar que os professores estão preocupados em formar cidadãos conscientes e em desenvolver a consciência social e política, o enunciador justifica o fato do porquê "estão falhando na sua tarefa mais simples", que é transmitir conteúdo. Ora, do lugar de fala do enunciador, somente há ensino de qualidade quando os professores desenvolvem conteúdos e capacidades cognitivas.

Portanto, do posicionamento econômico-educacional, a Educação de qualidade é aquela que transmite conteúdos e desenvolve a capacidade cognitiva, sendo essa a "tarefa mais simples" e dever primordial dos professores. No entanto, o enunciador, conforme 
enfatiza no recorte 1 , identifica que os professores valorizam outra concepção de Educação de qualidade: aquela que desenvolve o senso crítico. Com isso, orienta seu discurso para que os coenunciadores vejam a postura dos professores como inadequada.

É nesse sentido que o simulacro criado pelo enunciador exerce um papel relevante para que ocorra adesão dos coenunciadores pela desqualificação do Outro. A constituição do simulacro ocorre pelo tema discursivo "objetivo da educação e função dos professores". Sobre esse tema, o enunciador trabalha em dois movimentos: determinar o posicionamento do Outro, ou seja, o discurso dos professores: "desenvolver consciência politica", "formar cidadão crítico". No segundo momento, aponta essa atitude como falha, justificando que devido a isso, a educação é prejudicada, ou seja, não se atinge seu principal objetivo que é de transmitir o conteúdo e desenvolver a cognição. Em seguida, transforma o discurso do Outro em simulacro, como ilustramos no esquema seguir:

\section{Papel do professor/ objetivo da educação}

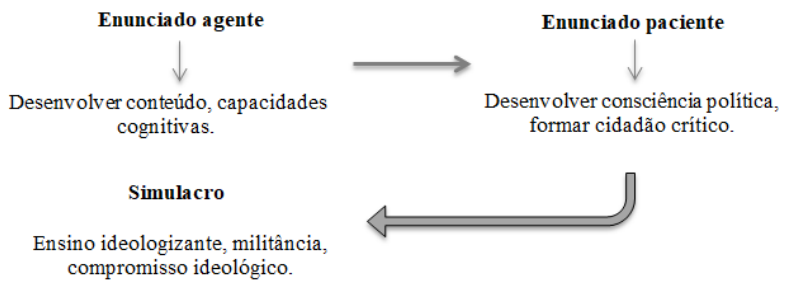

Esquema 1. Simulacro. Elaborado pelo autor

O simulacro é, neste caso, um processo de distorção do discurso do Outro, para poder deslegitimá-lo. O enunciador agente lê o 
discurso do Outro, mas, por considerá-lo ilegítimo, dá a ele novos efeitos de sentido de modo que possa depreciá-lo. Cria-se, assim, o simulacro: enunciado que somente existe em seu próprio discurso, não no do Outro. É do modo como o discurso agente lê o outro que se forma o simulacro.

Parecido com esse fenômeno interdiscursivo, podemos considerar que a noção "escola sem partido" bastante discutida nos últimos anos, atua de modo similar. A "escola partidária”, que influenciaria ideologicamente os alunos, é a leitura que um posicionamento discursivo faz do Outro. O discurso agente, do seu próprio lugar de fala, lê no Outro discurso, na prática dos professores, um ensino de inculcação ideológico-partidária, sendo esse o simulacro que constrói do Outro.

Em consequência, cria-se a fórmula discursiva "escola sem partido" como forma de combate ao discurso do Outro. Seria uma espécie de luta quixotiana contra moinhos de vento, tendo em vista que é um confronto ao próprio simulacro criado pelo posicionamento dos adeptos da "escola sem partido".

No recorte posterior, o simulacro é evidente:

\section{Recorte 3}

Nossas faculdades de formação de professores estão mais preocupadas em agradar ao pendor idealista de seus alunos do que em satisfazer suas necessidades técnicas. São cursos profundamente ideologizados e teóricos.

No recorte 3, o enunciador, ao construir o objeto do discurso "faculdades de formação de professores", caracteriza-o como ins- 
tituições que visam a agradar ao "pendor idealista" dos seus alunos: os futuros professores. $\mathrm{O}$ enunciador coloca, assim, tanto as instituições de formação de professores como os professores no mesmo lugar de enunciação. A imagem que o enunciador constrói dos professores é a de sujeitos que, mesmo antes de se tornarem profissionais e de se formarem, já eram "idealistas".

Ao mesmo tempo, o enunciado "pendor idealista", pelo interdiscurso, reitera os posicionamentos do discurso pedagógico-educacional sobre o tema "objetivo da educação e papel dos professores” em forma de simulacro. No discurso pedagógico, a definição para esse tema pode tomar formas como: missão de formar o sujeito crítico e autônomo, desenvolvimento do senso crítico, construção de uma sociedade mais justa. "Pendor idealista" é o modo como o posicionamento econômico-educacional lê o Outro. $\mathrm{Na}$ verdade, é o modo como ele vê aqueles que se inscrevem no posicionamento pedagógico-educacional. $\mathrm{O}$ simulacro atua, não somente como um enunciado depreciativo, mas também como uma imagem que o enunciador constrói do Outro.

Esse enunciado atribui ao posicionamento pedagógico-educacional o lugar marcado pelo subjetivismo, pela luta por convicções pessoais e político- partidárias. A construção do simulacro é, portanto, a construção de um lugar de fala do Outro, lugar da farsa e do erro, visto que a verdade, para o enunciador, já está posta no seu posicionamento, no lugar de onde ele enuncia.

Em "cursos profundamente ideologizados e teóricos", reforça-se ainda mais o lugar de fala, marcado pelo político-partidário: "ideologizados" é um forte simulacro para "formar cidadãos conscientes" ou de "desenvolver a consciência social e política das novas gerações”. Assim, o enunciador aponta que a atuação, tanto dos cursos quanto dos professores são posicionamentos "ideolo- 
gizados", vistos de modo negativo como convicções político-partidárias, que delegariam para segundo plano o papel do professor como transmissor de conhecimentos técnicos.

\section{Recorte 4}

Não há sanção ao professor ineficaz, nem incentivo ao professor obstinado. O professor que fracassa continuará recebendo seu salário, pois tem estabilidade. Seguirá, inclusive, sendo promovido, pois na maioria das redes a promoção se dá por tempo de serviço ou titulação, não por mérito. Esse professor não será nem incomodado: um dos pilares de grande parte de nossas redes é a autonomia da escola, a ideia de que ninguém pode dizer ao professor o que ou como ensinar.

No recorte 4, o enunciador critica o funcionamento do sistema educacional, por não funcionar de acordo com uma lógica de mérito e punição; assim, no seu ponto de vista, trata-se de um sistema injusto e ineficiente. As ideias de sanção e incentivo coadunam com o tema "funcionamento administrativo das instituições de ensino" em que o enunciador se opõe a um sistema em que não opere de acordo com o mérito.

Para o enunciador deve existir punição e premiação, para que um sistema funcione de modo eficaz. Além disso, aponta a ineficiência do sistema educacional público, ao estabelecer a promoção por tempo de serviço e titulação, mas não por mérito. Estabelece-se aqui a visão empresarial-administrativa, que marca o posicionamento econômico-educacional. 
Destacam-se por essa ótica, também, a valorização da iniciativa privada e a depreciação do sistema estatal. O sistema administrativo do Estado é mostrado como ineficiente, mantendo e até premiando maus funcionários que não serão "nem incomodados". Em seguida, critica o motivo da ineficiência do ensino público: a autonomia dada a esse sistema. Segue-se, assim, a depreciação do sistema estatal.

Destacamos que a noção de "autonomia" é fortemente marcada na LDB (1996) e valorizada no discurso do posicionamento pedagógico-educacional. Assim, o enunciador busca desconstruir essa noção, desvalorizando-a e depreciando-a em forma de um novo simulacro: o enunciador traduz "autonomia" como "a ideia de que ninguém pode dizer ao professor o que ou como ensinar". No recorte posterior, a noção de autonomia é novamente traduzida em forma de outro simulacro:

\section{Recorte 5}

Mesmo nesse sistema tão permissivo e ineficiente

Notemos que, no recorte 5, "autonomia" é traduzido como "sistema tão permissivo". O enunciador conduz o co-enunciador a entender a ideia de autonomia, noção valorizada pelo Outro, como falta de regras e controle, ou seja, um equivalente de desorganização e, consequentemente, de ineficiência administrativa. 
Do lugar de onde o enunciador projeta sua fala, a verdade é a de que o sistema educacional é imperado pela incompetência administrativa e por professores mergulhados no senso comum, em suas ideologias partidárias. São idealistas, por isso, não há aprendizagem eficiente, já que a falta de normas e controle provocada pelo sistema estatal ineficiente, faz com que esse sistema seja dominado por convicções pessoais, que pouco contribuem para o desenvolvimento da Educação e, consequentemente, para o desenvolvimento econômico.

Contudo, trata-se de uma verdade historicamente constituída por um posicionamento. Se um discurso nasce do avesso do Outro, todo posicionamento e sua rede de verdades devem ser postos em contraste com as verdades do Outro. Neste capítulo, refletimos sobre os semas valorizados no discurso inscrito no posicionamento econômico-educacional. É necessário, também, que esse processo analítico seja ampliado para outros posicionamentos que atravessam os discursos do campo educacional, com ênfase naqueles divulgados pela mídia.

O objetivo neste capítulo foi de analisar como se constituem os posicionamentos sobre a Educação veiculados em discursos da revista Veja. Acerca disso, notamos que o lugar de fala do enunciador é o posicionamento econômico-educacional. Corrobora com esses resultados a pesquisa desenvolvida em Baptista (2015), na qual pudemos confirmar que o articulista mais representativo para tratar sobre a Educação na revista também assume o discurso do posicionamento econômico-educacional.

Além disso, visamos a identificar o funcionamento enunciativo do posicionamento econômico-educacional: sua identidade enunciativa. $\mathrm{O}$ esquema abaixo resume as noções que marcam a identidade desse posicionamento, com os semas valorizados por 
aqueles que enunciam desse lugar; portanto, considerados legítimos nos enunciados do posicionamento econômico-educacional.

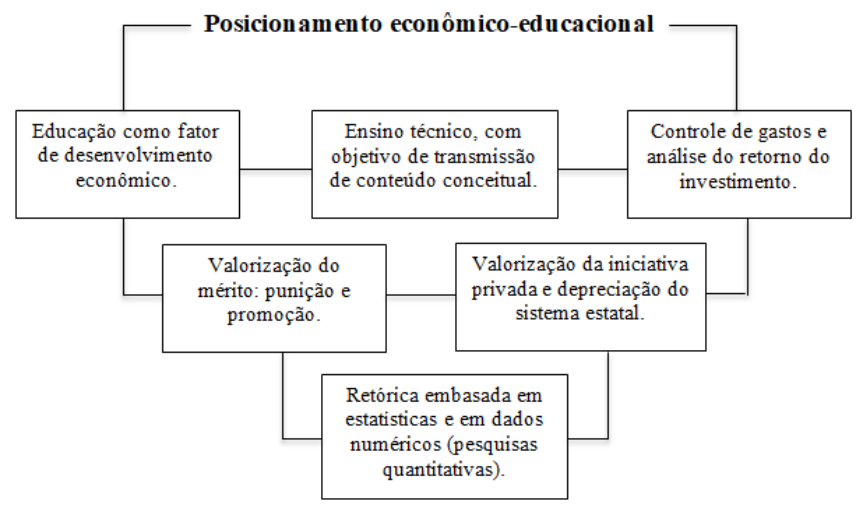

Esquema 2. Identidade de posicionamentos. Elaborado pelo autor.

Encontramos discursos veiculados na mídia, assim como em diversos campos discursivos, como o político, que se embasam nas premissas apontadas acima, inscrevendo-se no posicionamento econômico-educacional, mesmo que não se deem conta disso. Dois motivos são determinantes para que isso ocorra. $\mathrm{O}$ primeiro é o fato

de que a educação é um campo interpelado por outros, refletindo as lutas e interesses em voga em cada conjuntura histórica. Assim, facilita-se a compreensão de que, na atualidade, com a força tomada pela economia nas relações sociais, os embates do campo econômico repercutem na educação e buscam direcioná-la (BAPTISTA, 2015, p. 27). 
O hibridismo que caracteriza o campo discursivo educacional atenua os posicionamentos do próprio campo, como o discurso pedagógico-educacional. Assim, há o atravessamento interdiscursivo de posicionamentos diversos no campo discursivo educacional. Na atualidade, é difícil conceber a Educação distanciada da esfera política, ou seja, a Educação torna-se um campo político-educacional. Tais domínios sobre o campo da Educação nem sempre são positivos. Nesse sentido, é necessário refletirmos sobre as relações de poder e de domínio sobre o campo e, principalmente, agirmos para que as ciências da educação atuem na manutenção do discurso pedagógico-educacional. Lembremos que, na atual conjuntura, o legado de pensadores como Paulo Freire é ameaçado por posicionamentos políticos ${ }^{8}$.

O segundo ponto, que esclarece a forte legitimidade do posicionamento econômico-educacional, é o fato de esse posicionamento usufruir da legitimidade social que a Economia detém. Em uma sociedade de organização político-econômica capitalista, na qual o desenvolvimento econômico tornou-se o mito dominante, a Economia é uma ciência de suprema legitimidade, que dita e norteia os novos rumos da ordem mundial. Nessa marcha incessante para o desenvolvimento econômico, a Educação torna-se meio e não fim. Em outras palavras, a Educação é apenas instrumento para o desenvolvimento econômico. Assim, as avaliações, de níveis nacional e internacional, mensuram a aprendizagem em forma de capital, de produto sem sujeitos.

8 Recordamos uma dessas ameaças em que o Procurador Federal em Goiás, Wesley Miranda Alves defendeu a queima de livros do educador Paulo Freire em praça pública. https://www.revistaforum.com.br/procurador-de-goias-defende-queima-de-livros-de-paulo-freire-em-praca-publica/. Acessado em $01 / 09 / 2018$. 


\section{Considerações finais}

Embora a análise do interdiscurso proposta por Maingueneau tenha vindo a público, há mais de 30 anos, pudemos notar sua relevância na construção de um dispositivo teórico-analítico que dê acesso às camadas mais profundas da interação (inter)discursiva. Contudo, pela complexidade de tal dispositivo e pela dificuldade de compreensão de uma obra não muito acessível aos iniciantes em $\mathrm{AD}$, há muito ainda a ser explorado acerca deste dispositivo teórico profícuo.

Vimos que as noções de campo, interincompreensão e simulacro, permitiram-nos identificar o funcionamento interdiscursivo no discurso do campo educacional. Esse funcionamento revela como o plano da linguagem enlaça-se ao plano histórico-social, isto é, como processos históricos inscrevem-se no discurso. $\mathrm{O}$ discurso sobre a Educação veiculado na mídia brasileira não é um discurso gratuito e desinteressado, pois quem enuncia fala de um lugar constituído historicamente, por semas aceitos como verdadeiros em uma relação de interincompreensão com o Outro de seu discurso.

Ao dar espaço para o posicionamento econômico-educacional, a mídia atribui-lhe legitimidade e aceita seus semas como verdadeiros. Mas há espaço na mídia para outros posicionamentos e outras verdades?

O posicionamento econômico-educacional, por usufruir de significativa legitimidade na atual conjuntura histórica, torna-se um posicionamento decisivo no campo educacional, pois aliado ao liberalismo político-econômico, passa a deliberar no interior do campo educacional e a defini-lo, ao mesmo tempo em que entra em conflito com os posicionamentos antagônicos no interior desse campo. 
Nessa direção, o universo de sentidos que esses discursos instauram nos remete à retórica dominante de que a Educação deve viabilizar o desenvolvimento econômico. Respaldado em dados estatísticos, no qual os números tornam-se recurso de autolegitimação, esse posicionamento representa um momento histórico-social de desordem política causada por uma administração pública incompetente, cujos interesses vão de encontro aos dos cidadãos. Nesse contexto, a Educação é apontada como um lugar dominado por profissionais incompetentes e mergulhados no senso comum. Nesse sentido, os enunciadores do discurso econômico-educacional defendem

que o sistema educacional vai de mal a pior e a única saída é render-se à lógica administrativo-econômica, ou seja, à mercantilização da Educação, de modo que o Estado deixe de ser o promotor e torne-se apenas concessionário da Educação. Assim, poderia surgir uma escola de gestão eficiente para competir no mercado e as avaliações sistemáticas de amplitude nacional e internacional produziriam dados quantitativos que, por sua vez, possibilitariam o ranqueamento e a auditoria educacional (BAPTISTA, 2015, p. 117).

Todavia, esse discurso, de aparente preocupação social, no qual a Educação tem como única finalidade o crescimento econômico, camufla um mundo desumanizado, em que os sujeitos são reificados em nome do crescimento econômico. Essa finalidade única justifica desde a exclusão social do sujeito aprendente, sem face, até as más condições de trabalho do profissional da educação.

Por esse motivo, é necessário o pensamento crítico acerca dos discursos que permeiam a Educação. É preciso entender que não 
há verdade absoluta sobre o papel da Educação e de que esse papel deve ser pensado de acordo com a sociedade à qual aspiramos.

\section{Referências}

BAPTISTA, C. A. As faces do autor: autoralidade nos discursos de Claudio de Moura Castro. Dissertação (Mestrado em Língua Portuguesa). Pontifícia Universidade Católica de São Paulo- PUC-SP. São Paulo, p. 147, 2015.

BRESSER-PEREIRA, L. C. Os dois métodos e o núcleo duro das ciências econômicas. Revista de Economia Política, v. 29, nº 2 (114), p. 163-190, abr./jun. 2009.

CHARAUdeAU, P. Discurso das mídias. São Paulo: Contexto, 2015.

CHARAUDEAU, P.; MAINGUENEAU, D. Dicionário de Análise do Discurso. São Paulo: Contexto, 2008.

EMERICK, B. Matemática na economia: bom ou ruim? 18 jun. 2013. Disponível em: <www.mises.org.br/Article.aspx?id=1627>. Consultado em: 01/08/ 2014.

IOSCHPE, G. O que pensam os professores brasileiros. Disponível em: https:/veja.abril.com.br/educacao/o-que-pensam-os-professores-brasileiros/ Consultado em: 20/05/2018.

MAINGUENEAU, D. Gênese dos discursos. Curitiba: Criar, 2008a. . Cenas da enunciação. São Paulo: Parábola, 2008 b.

SUTTER, D. Where Would Adam Smith Publish Today?: The Near Absence of Math-free Research in Top Journals. Econ Journal Watch, v. 4, n. 2, p. 230-240, maio. 2007. Disponível em: <econjwatch. org/articles/where-would-adam-smith-publish-today-the-near-absence-of-math-free-research-in-top-journals>. Consultado em: 10 out. 2014 . 